University of Wollongong

Research Online

Faculty of Engineering and Information

Faculty of Engineering and Information

Sciences - Papers: Part B

Sciences

2018

Evaluating the Properties of Mixtures of Steel Furnace Slag, Coal Wash, and Rubber Crumbs Used as Subballast

Buddhima Indraratna

University of Wollongong, indra@uow.edu.au

Yujie Qi

University of Wollongong, qyujie@uow.edu.au

Ana Heitor

University of Wollongong, aheitor@uow.edu.au

Follow this and additional works at: https://ro.uow.edu.au/eispapers1

Part of the Engineering Commons, and the Science and Technology Studies Commons

Research Online is the open access institutional repository for the University of Wollongong. For further information contact the UOW Library: research-pubs@uow.edu.au 


\title{
Evaluating the Properties of Mixtures of Steel Furnace Slag, Coal Wash, and Rubber Crumbs Used as Subballast
}

\author{
Abstract \\ Steel furnace slag (SFS) and coal wash (CW) are two common by-products from the coal-mining and steel \\ industries in Australia. Rubber crumbs (RC) is a material derived from waste tires contributing to \\ environmental problems in most developed countries. Reusing and recycling these waste materials is not \\ only economically beneficial and environmentally sustainable, but it also helps to address geotechnical \\ problems such as track degradation. In this study, SFS, CW, and RC are blended to explore the feasibility \\ of obtaining an energy-absorbing capping layer with properties similar or superior to conventional \\ subballast. Comprehensive laboratory investigations have been carried out to study the geotechnical \\ properties of SFS + CW + RC mixtures, from which seven parameters (including gradation, permeability, \\ peak friction angle, breakage index, swell pressure, strain energy density, and axial strain under cyclic \\ loading) were used to evaluate the properties of these mixtures used as subballast. It was found that a \\ mixture with SFS:CW $=7: 3$ and $10 \% \mathrm{RC}(63 \% \mathrm{SFS}, 27 \% \mathrm{CW}$, and $10 \% \mathrm{RC})$ is the best mixture for subballast. \\ Disciplines \\ Engineering | Science and Technology Studies

\section{Publication Details} \\ Indraratna, B., Qi, Y. \& Heitor, A. (2018). Evaluating the Properties of Mixtures of Steel Furnace Slag, Coal \\ Wash, and Rubber Crumbs Used as Subballast. Journal of Materials in Civil Engineering, 30 (1), \\ 04017251-1-04017251-9.
}




\title{
Evaluating the Properties of Mixtures of Steel Furnace Slag, Coal Wash, and Rubber Crumbs Used as Subballast
}

\section{Buddhima Indraratna}

$\mathrm{PhD}$ (Alberta), MSc and BSc-Hons (London), FTSE, FIEAust, FASCE, FGS, FAusIMM, FIES, DIC, CEng, CPEng Distinguished Professor, Research Director and Foundation Director, Civil Engineering, Centre for Geomechanics and Railway Engineering, Faculty of Engineering, University of Wollongong, Wollongong, NSW 2522, Australia

\author{
Yujie Qi \\ PhD Candidate \\ Centre for Geomechanics and Railway Engineering, Faculty of Engineering, \\ University of Wollongong, Wollongong, NSW 2522, Australia
}

\begin{abstract}
Ana Heitor
$\mathrm{PhD}$

Lecturer, Centre for Geomechanics and Railway Engineering, Faculty of Engineering, University of Wollongong, Wollongong, NSW 2522, Australia
\end{abstract}

\author{
$\dagger$ Author for correspondence: \\ Prof. Buddhima Indraratna \\ School of Civil Engineering, \\ Faculty of Engineering, University of Wollongong \\ Wollongong, NSW 2522 \\ AUSTRALIA \\ Ph: +61242213046 \\ Fax: +61 242213238 \\ Email: indra@uow.edu.au
}

To be submitted to: Journal of Materials in Civil Engineering 
37 Abstract: Steel furnace slag (SFS) and coal wash (CW) are two common by-products from coal mining and steel industries in Australia. Rubber crumbs (RC) is a material derived from waste tyres contributing to environmental problems in most developed countries. Reusing and recycling these waste materials is not only economically beneficial and environmentally sustainable, but it also helps to address geotechnical problems such as track degradation. In

42 this study, SFS, CW, and RC are blended to explore the feasibility of obtaining an energy 43 absorbing capping layer with properties similar or superior to conventional subballast.

44 Comprehensive laboratory investigations have been carried out to study the geotechnical 45 properties of $\mathrm{SFS}+\mathrm{CW}+\mathrm{RC}$ mixtures, from which seven parameters (including gradation, 46 permeability, peak friction angle, breakage index, swell pressure, strain energy density, and 47 axial strain under cyclic loading) were used to evaluate the properties of these mixtures used as subballast. It was found that a mixture with SFS:CW=7:3, and 10\% RC (63\% SFS, 27\% $\mathrm{CW}$, and $10 \% \mathrm{RC}$ ) is the best mixture for subballast.

50 KEYWORDS: Steel furnace slag; coal wash; rubber crumbs; subballast; reuse and recycling of waste materials 
54 CW and SFS are granular by-products of the coal mining and steel industries, respectively.

$55 \mathrm{CW}$ is produced during the coal washing process to separate coal from its impurities using physical and chemical methods, whereas SFS is produced while converting iron to steel in a basic oxygen furnace (BOF). The production of these wastes in Australia alone can be several hundreds of millions of tonnes per year (Leventhal and de Ambrosis, 1985). While, the reuse of these granular waste by-products has substantial advantages from an economical and environmental perspective, their individual adverse geotechnical properties, i.e. breakage potential for coal wash (Indraratna, 1994, Heitor et al., 2016) and volumetric instability (swelling) for steel furnace slag (Wang, 2010) may prevent their use as individual fill materials. Past research studies have reported that the mixtures of CW and SFS can reduce particle breakage as well as control volumetric expansion (Indraratna, 1994; Chiaro et al., 2013; Heitor et al., 2014), and selected blends ratios were successfully employed as a structural fill for Port Kembla Outer Harbour reclamation (Chiaro et al., 2013).

Furthermore, based on trace element concentration tests, neither coal wash nor steel furnace slag has been found to pose any significant risk of environmental contamination. The commercial use of these engineered fills has already been approved by the Environment Protection Authority of the state of New South Wales (NSW EPA, 2014). Similarly, chemical test results reported by Lim and Chu (2006) indicate that the heavy metal concentrations contained in a typical steel slag leachate were significant lower than the threshold toxicity limits stipulated by the US EPA.

The application of scrap tyres in civil works includes soil reinforcement in road construction, ground erosion control, vibration isolation, non-structural sound barrier fills, slope 
to asphalt (Sheikh et al. 2013; Gibson et al., 2012; Qi et al., 2006). Recycled tyres are typically granulated or shredded and exhibit frictional behaviour, low unit weight of solids (the specific gravity generally ranges from 1.00 to 1.36), low bulk density, high hydraulic conductibility, exothermic reactions and high compressibility (Senetakis et al., 2012; Zheng and Kevin, 2000; Edil and Bosscher, 1994).

Although past studies have proposed viable and cost-effective alternative solutions using these waste materials (coal wash, steel furnace slag, and scrap tyres) in construction projects either individually, blended or mixed with soil, no past study has quantified the behaviour of the mixture of these three waste materials. Further, while the behaviour of selected blends of $\mathrm{CW}$ and SFS has proven to conform to the performance criteria adopted for Port reclamation (Tasalotti et al., 2015), it was limited to monotonic loading conditions. Under cyclic loads such as those encountered in a track substructure, the incidence of CW particles breakage is likely to be exacerbated. The addition of rubber crumbs to the mixtures can promote enhanced strain energy absorption while simultaneously increasing the overall permeability, reducing particle breakage and controlling the expansion of the blended mix.

This study has attempted to develop an energy absorption mixture using coal wash, steel surface slag, and rubber crumbs as subballast in a railway system in a way that is economically and environmentally friendly, while also minimizing track degradation and the need for freshly quarried natural aggregates.

\section{Parameters Used to Evaluate the Waste Mixtures}

The main functions of the subballast layer are filtration, drainage, and controlled stress distribution reaching the soft subgrade soil. While a suitable gradation prevents the upward migration of fine particles from subgrade to the ballast layer, a relatively high permeability sustains effective drainage of the substructure. Further, the subballast also requires adequate 
stiffness to control load distribution to the subgrade. For selecting the $\mathrm{SFS}+\mathrm{CW}+\mathrm{RC}$ mixtures

102

103

104 used as a suitable subballast layer material, the three functional parameters i.e. gradation, permeability coefficient, as well as the peak friction angle should be considered firstly (Table 1). The required range of parameters was set to ensure the optimum composition of $\mathrm{SFS}+\mathrm{CW}+\mathrm{RC}$ mixtures having mechanical properties similar to or superior to traditional subballast materials.

The adverse individual geotechnical properties of the three granular wastes, i.e. breakage, swelling and low shear strength must be controlled properly to enable the $\mathrm{SFS}+\mathrm{CW}+\mathrm{RC}$ mixtures to be used as subballast. Thus three other parameters are used to control the adverse geotechnical properties of the SFS+CW+RC mixtures (Table 1). The breakage index (BI) should not exceed that of conventional subballast ( $2 \%$ for crushed rock upon shearing with $\sigma^{\prime}{ }_{3}=40 \mathrm{kPa}$ ) in order to maintain its function as a filter. The swell pressure should be less than the minimum overburden and wheel load stresses (i.e. $30 \mathrm{kPa}$; Ferreira \& Teixeira, 2012). The axial strain of the optimum mixture under cyclic loading should be less than the mean acceptable axial strain of subballast (0.02; Teixeira et al., 2006).

The addition of rubber crumbs enhances the potential for the waste mixtures to absorb strain energy from external loads, thus contributing to a reduction in ballast degradation and the stresses transmitted to the subgrade. The strain energy density adopted to evaluate the energyabsorbing capacity is another parameter considered when optimizing the waste mixtures (Table 1).

In order to obtain the above parameters, comprehensive and detailed laboratory investigations were carried out on traditional subballast (crushed rock) and SFS+CW+RC mixtures. The testing program consisted of compaction tests, permeability tests, monotonic and cyclic 
triaxial tests, swell pressure tests and breakage evaluation through wet sieving after compaction and shearing.

\section{Laboratory Testing Program}

127 Materials

128 The source materials selected were a Dendrobium coal wash produced by Illawarra Coal and a SFS produced ASMS (Australia Steel Milling Services), respectively. Coal wash is 130 predominantly composed quartz and residual coal, with illite and kaolinite as the main clay minerals. Trace quantities of calcite, pyrites and sulphur were also detected in the x-ray diffraction analysis. The CW aggregates are composed of both angular and relatively flaky grains, and typically exhibits dual porosity. The steel furnace slag is composed mainly of metal compounds (e.g. $\mathrm{Fe}_{2} \mathrm{O}_{3}, \mathrm{SiO}_{2}$ ) and free lime $(\mathrm{CaO})$. The chemical composition of $\mathrm{CW}$ and SFS determined by X-ray diffraction analysis provided by the ASMS and the BHP Illawarra Coal is shown in Table 2.

$\mathrm{RC}$ was from waste tyres and in this study three different size $(0-2.3 \mathrm{~mm}, 0.3-3 \mathrm{~mm}$, and $1-7$ $\mathrm{mm}$ ) rubber crumbs were used. The traditional subballast material (crushed rock) was obtained from Bombo quarry near Wollongong, New South Wales, Australia. The particle size distribution (PSD) curves of SFS, CW, RC, and crushed rock are shown in Fig. 1. The dry method was used to sieve oven-dried SFS, crushed rock, and air-dried rubber crumbs whereas the wet method was used for CW. SFS and CW can be classified as well-graded gravel with silty-sand (GW-GM), and well-graded sand with gravel (SW) (unified soil classification system, USCS), respectively, while RC can be referred to as granulated rubber (ASTM D6270, 2008). 
148 In order to satisfy the filter criteria of subballast and exclude the influence of gradation, all

149 the mixtures tested in this study were mixed to the same gradation (the target PSD) selected based on conventional subballast gradation adopted in Victoria and Queensland (Australia) also shown in Fig.1. Three waste materials (SFS, CW, and RC) were blended into mixtures with different ratios of SFS:CW (5:5, 6:4, 7:3, 8:2, and 9:1) and different amounts of rubber crumbs (RC) $(0 \%, 10 \%, 20 \%, 30 \%$, and $40 \%)$. The waste mixtures with selected blend ratios were prepared by mixing different percentages of oven-dried SFS and CW, and air-dried RC by weight in order to reach the target PSD. In this study the three materials were mixed by weight rather than by volume. This is because "by weight" percentage could be more accurately measured during mixture preparation, as the volume of solids depends on the specific gravity and will also vary with the temperature, water content, and the age of rubber particles (Edil and Bosscher, 1994; Zheng \& Kiven, 2000). Previous studies such as Navarro and Gamez, (2012), Xu et al., (2013), and Al-Khateeb \& Ramadan (2015) also prepared the rubber-soil mixtures based on weight $\%$.

To achieve the target PSD, the waste materials were sieved and separated into different particle sizes, and the exact mass corresponding to a given size range provided by the target PSD was weighed and blended thoroughly to obtain a uniform blend. A past study by Tasalloti et al. (2015) has demonstrated this method earlier. All the specimens for permeability tests, monotonic and cyclic triaxial tests, and swell pressure tests were prepared with the optimum moisture content and compacted to achieve the initial dry unit weight equal to $95 \%$ of their $\gamma_{\mathrm{dmax}}$ to simulate subballast behaviour under typical placement conditions. The specimens for monotonic and cyclic triaxial tests are $50 \mathrm{~mm}$ in diameter and $100 \mathrm{~mm}$ in height. The maximum particle size of the materials is around $7 \mathrm{~mm}$, thus the ratio of specimen diameter $(50 \mathrm{~mm})$ to the maximum particle size is around 7.1. Previous studies 
have shown that the equipment boundary size effects can be neglected when this ratio exceeds at least 6 (Marachi et al., 1972; Indraratna, 1994).

The monotonic triaxial tests were carried out in accordance with ASTM D7181 (2011) following three stages, i.e. saturation, consolidation, and shearing. During the saturation stage, the air was firstly expelled by flooding the deaired water from the bottom of the specimen, then back pressure was applied with the increasing rate of $1 \mathrm{kPa} /$ minute until $500 \mathrm{kPa}$ was achieved. This stage was completed when the Skempton's B-value exceeded 0.98, and then isotropic consolidation was conducted until the desired mean effective confining pressure was achieved to $40 \mathrm{kPa}$ to simulate common in situ heavy haul track conditions. The confining pressure for subballast materials of heavy haul tracks is typically $\leq 40 \mathrm{kPa}$ in the field, and it depends upon the axle loads, embankment heights and the depth of subballast and structural fill (Indraratna et al., 2011; Indraratna et al, 2014). After consolidation, monotonic shearing was conducted with a relatively slow constant strain rate of $0.2 \mathrm{~mm} / \mathrm{min}$ to ensure fully drained conditions were maintained during shearing, and the triaxial tests were completed when $25 \%$ axial strain was achieved. Once the tests were completed, sieving procedure was repeated and particle breakage was evaluated. Membrane correction was applied using ASTM D7181 (2011) procedure assuming an axial strain of 25\%, rubber membrane thickness of $0.25 \mathrm{~mm}$, and Young's modulus of rubber membrane of $1100 \mathrm{kPa}$, resulting in a deviator stress correction of $5.7 \mathrm{kPa}$ which is insignificant ( $<3 \%$ error) for the test specimens.

The stress-controlled drained cyclic triaxial tests were carried out to investigate the axial displacement of SFS+CW+RC mixtures with SFS:CW=7:3 and different amounts of RC (0\%, $10 \%, 20 \%, 30 \%$, and $40 \%$ ) following the procedure suggested by ASTM D5311/D5311M (2013). The specimens were $50 \mathrm{~mm}$ in diameter and $100 \mathrm{~mm}$ in height. The cyclic loading tests were conducted following three stages, i.e. saturation, consolidation, and cyclic loading. 
197 The saturation and consolidation stages were the same with monotonic triaxial tests. The cyclic loading stage was conducted at $\mathrm{CSR}=0.8$ (cyclic stress ratio, Eq. 1). Accordingly, the deviator stress used is governed by ${\sigma^{\prime}}_{3}$ and the cyclic stress ratio, CSR. For CSR $=0.8$, and a confining pressure of ${\sigma^{\prime}}_{3}=40 \mathrm{kPa}$, the corresponding deviator stress (axial stress) is $64 \mathrm{kPa}$. This value is in line with the observed capping stress conditions (axial stress ${\sigma^{\prime}}_{a} \leq 70 \mathrm{kPa}$ ) in typical freight tracks in NSW, Australia (Indraratna et al., 2011). A loading frequency $f=5 \mathrm{~Hz}$ was used to simulate a quasi-static condition which is usually adopted in track design procedures, so that the mass inertia effects of the specimen can be neglected (Suiker et al., 2005). The cyclic loading test was continued for 50000 cycles to ensure that all the tests would end with an approximately stable axial strain.

$$
C S R=\frac{\sigma_{a}}{2 \sigma_{3}^{\prime}}
$$

In the above, CSR is the cyclic stress ratio; $\sigma_{\boldsymbol{a}}$ is the average single amplitude cyclic axial stress; and $\boldsymbol{\sigma}^{\prime}{ }_{\mathbf{3}}$ is the effective confining pressure.

The swell pressure of the selected blends was evaluated through constant volume tests using CBR moulds and a hot water bath at temperature of $40^{\circ} \mathrm{C}$ (as rubber materials melt around $\left.50-60^{\circ} \mathrm{C}\right)$ to accelerate the tests procedure. In these tests, the swelling of the specimen $(158$ $\mathrm{mm}$ in diameter and $112 \mathrm{~mm}$ high) was prevented by constraining the vertical swell, and the maximum pressure measured by a load cell was monitored (Basma et al., 1995). The swell pressure can be inferred after a period of typically 20 days, upon which variations in the vertical pressure were considered negligible.

\section{Results and Discussion}

\section{Index properties}


218 The basic geotechnical properties (specific gravity $\mathrm{G}_{\mathrm{s}}$, maximum dry density $\gamma_{\mathrm{dmax}}$, optimum

219

220

221

222

223

224 moisture content (OMC), and permeability coefficient $k$ ) of SFS, CW, RC, their mixtures, and crushed rock are shown in Table 3. Of these three waste materials, SFS is the densest $\left(G_{s}=3.43\right)$, and $R C$ is the lightest $\left(G_{s}=1.15\right)$. Thus, the maximum dry unit weight $\left(\gamma_{d m a x}\right)$ increases as the amount of SFS increases, and decreases as the amount of RC increases. The optimum moisture content changes slightly from $12.5 \%$ to $15 \%$ as the ratio of SFS:CW, and the amount of $\mathrm{RC}$ changes. It is of interest to note that the void ratio $\left(e_{0}\right)$ of the mixtures after compaction at OMC increases as the RC content and the ratios of SFS:CW increase. This will partially explain the change of permeability coefficient of the mixtures in the following discussion.

The permeability coefficients for the $\mathrm{SFS}+\mathrm{CW}+\mathrm{RC}$ mixtures were evaluated by constant head permeability tests (ASTM D2434, 2006b). The tests results for specimens with different amounts of rubber compacted at their OMC are plotted in Fig. 2. The permeability of these waste mixtures increases with larger content of rubber crumbs as well as the increasing ratios of SFS:CW, because a larger amount of RC or SFS results in an increase in the corresponding void ratio. This is consistent with observations reported by Chiaro et al. (2013) for SFS and $\mathrm{CW}$ blends. It seems that all the waste mixtures with SFS:CW $\geq 5: 5$, and $\mathrm{RC} \geq 10 \%$ could ensure a good drainage condition, as the 'good drainage' permeability range for subballast was between $10^{-5} \mathrm{~m} / \mathrm{sec}$ and $10^{-3} \mathrm{~m} / \mathrm{sec}$ (Trani and Indraratna, 2010).

\section{Stress-strain behaviour}

Figs. 3 (a) and (b) show the typical stress-strain and volumetric strain behaviour of the waste mixtures with different amounts of RC and different ratios of SFS:CW, respectively. It can be observed that the peak deviator stress decreases as the amount of RC increases (Fig. 3a), and increases as the dosage of SFS:CW increases (Fig. 3b). This is not surprising considering that 
rubber has very low shear strength comparatively to SFS and CW materials, and SFS has superior stiffness compared to CW. Similar observations were reported by Tasalloti et al., (2015) for CW-SFS blends. All the specimens exhibited a predominantly strain softening behaviour accompanied by a contractive-dilative response. As expected, an increase in RC results in larger compression, and an increase in the ratios of SFS:CW generates greater dilation, but no variation of the peak compression volumetric strain was observed for different ratios of SFS:CW while maintaining the same RC content. This indicates that the contraction response is mainly governed by the amount of RC. Moreover, the axial strain corresponding to the peak deviator stress increases with the addition of $\mathrm{RC}$ indicating the stress-strain behaviour changes from brittle to a predominantly ductile response, likely due to an increasing rubber-to-rubber interaction in the skeleton of the mixtures. Similar observations have been reported by Kim and Santamarina (2008) for mixtures of sand and rubber tyre crumbs.

\section{Peak friction angle}

The friction angle of the waste mixtures determined considering the peak deviator stress $\left(\emptyset_{\text {peak }}^{\prime}\right)$ is shown in Fig. 4 (a) and Table 4. As with the peak stress, the peak friction angle decreases as the amount of RC increases, and it increases as the ratio of SFS:CW increases. It is noteworthy that for the ratios of SFS:CW smaller than 5:5, the addition of RC exceeding $10 \%$ results in $\emptyset_{\text {peak }}^{\prime}$ being smaller than those typically adopted for traditional subballast (e.g. crushed rock, $\emptyset_{\text {peak }}^{\prime}=49^{\circ}$ ). In contrast, the waste mixtures having ratios of SFS:CW $\geq$ 7: 3 , and $\mathrm{RC} \leq 20 \%$ exhibit a higher shear strength than conventional subballast (Fig. 4a).

\section{Particle breakage}

264 Particle breakage should be evaluated to quantify the level of degradation that a granular material undergoes when subjected to impact loading and shearing. Typically the incidence 
of particle breakage can be quantified considering the breakage index (BI) that relies on the

267

268

269

270

271

272

273

274

275 evaluation of the initial and final gradations (Indraratna et al. 2005) shown in the top right corner of Fig. 4 (b). In this study the BI index was determined for the selected waste mixtures with different ratios of SFS:CW and RC content upon shearing at $\sigma_{3}^{\prime}=40 \mathrm{kPa}$. The summary of results is shown in Fig. 4 (b), while the experimental data is listed in Table 4. As expected, the addition of rubber crumbs significantly reduced particle breakage in the waste mixtures. This suggests that loads can be buffered as the rubber crumbs deform (i.e. strain energy absorption), which then reduces breakage of CW and SFS. Moreover, when the ratio of SFS:CW increases, particle breakage also decreases due to the smaller content of CW.

The breakage index (BI) of conventional subballast (crushed rock) measured was $2 \%$, as also noted in Fig. 4 (b). If a similar performance to that of conventional subballast is to be achieved, it seems that blends having ratios of SFS:CW $\geq 7: 3$ and $10 \% \mathrm{RC}$ will be sufficient to ensure particle breakage within acceptable limits (Fig. 4b).

\section{Energy absorption}

The strain energy density is the parameter usually adopted for evaluating the energy absorbed in shearing tests, and it can be computed considering the area under the shear stress-strain curve up to failure (Fig. 4c), as represented by Eq. 2

$$
E=\int_{0}^{\gamma_{f}} \tau d \gamma
$$

where $E$ is the strain energy density $(\mathrm{kPa}), \gamma_{f}$ is the shear strain (dimensionless) up to failure, and $\tau$ is the shear strength $(\mathrm{kPa})$.

The strain energy density up to the failure of various waste mixtures computed based on the triaxial drained shearing results is plotted in Fig. 4 (c). When the same RC content was maintained, increasing the rate of SFS:CW only generated little increase of the strain energy 
density. However, there is a substantial increase in strain energy density as the RC content increases indicating the high ductility of rubber crumbs. Interestingly, the strain energy density of the waste mixtures without rubber crumbs is similar to traditional subballast, which confirms that it is the addition of RC to the waste mix that enhanced its energy absorbing capacity (Fig. 4c), although once $10 \%$ of $\mathrm{RC}$ is exceeded the increase is marginal. This is likely related to the decrease in shear strength (e.g. Fig. 4a) and decrease in particle breakage (e.g. Fig. 4b). On this basis, it seems that $10 \% \mathrm{RC}$ is sufficient for the mixture to serve as an energy absorbing layer while tolerating an acceptable reduction in shear strength.

\section{Swell pressure}

Fig. 5 and Table 4 report the results of swell pressure $P_{\text {swell }}$ of the $\mathrm{SFS}+\mathrm{CW}+\mathrm{RC}$ mixtures obtained. As expected, the increase in $\mathrm{CW}$ and $\mathrm{RC}$ proportions in the mixtures effectively contributes to a reduction in the swell pressure of the waste mixtures. For instance, for the same amount of $\mathrm{RC}$, the swell pressure of the waste mixtures decreases with the decreasing ratio of SFS:CW in the mixtures (Fig. 5a). Similarly, the addition of RC while maintaining the same ratio of SFS:CW contributes to a reduction in the swell pressure because the volumetric expansion caused by the hydration of free lime present in SFS can be partially counteracted as the rubber crumbs deform. However, for RC content greater than $10 \%$, the swell pressure of the waste mixtures only decreases marginally (Fig. 5b). This indicates that $10 \%$ would be an optimum percentage of RC to control the swelling of the SFS+CW+RC mixtures.

\section{Axial displacement under cyclic loading}

Fig. 6 shows the axial strain $\varepsilon_{a}$ of SFS+CW+RC mixtures for different $\mathrm{RC}$ content changing with loading cycles. Almost $90 \%$ axial strain of the all the specimens is achieved in the first 500 cycles; axial displacement increases marginally in the subsequent cycles and becomes 
relatively stable after 50000 cycles. It was noted that with the increasing amount of RC, the axial strain of the SFS+CW+RC mixtures increased but at a decreasing rate (Fig. 7). The presence of $\mathrm{RC}$ in the waste material mix makes it increasingly compressible. Both field measurements and laboratory triaxial testing indicate that the mixtures undergo overall compression upon cyclic loading, and there is no volumetric dilation as the radial (lateral) strains are very small. For a maximum axial strain of 0.012 for the mix with SFS:CW=7:3, and $10 \% \mathrm{RC}$, the associated lateral tensile strain is less than $0.002(0.2 \%)$, which is very small to be of concern. Also, no test specimens have indicated any cracking during triaxial compression which confirms that the occurrence of adverse tensile strains is not a concern. The average axial strain of conventional subballast is in the proximity of 0.02 (Teixeira et al., 2006), and therefore based on these test results, the amount of RC in the waste mixtures should not exceed about $18 \%$.

\section{Identifying the optimum SFS+CW+RC Mixture}

In the test program, all the waste mixtures were suitably graded because they have the same gradation as conventional subballast. Moreover, the permeability, energy-absorbing capacity and particle breakage characteristics of all the waste mixtures with $\mathrm{RC} \geq 10 \%$ and SFS:CW $\geq 5: 5$ satisfy the required range in Table 1 . However, having a greater proportion SFS induces increased swelling, and greater the CW content, the lower the shear strength, i.e. the ratio of SFS:CW plays a crucial role in governing the level of shear strength and the swell pressure of the waste mixtures. To select the optimum mixture, the ratio of SFS:CW was first justified by using the test results of the shear strength and swell pressure of waste mixtures with $10 \% \mathrm{RC}$, and then the amount of RC was optimised using the comprehensive test results of the waste mixtures with the selected ratio of SFS:CW. 
Fig. 8 shows the ratio of SFS:CW was justified in the optimum mixture according to the peak friction angle and swell pressure. To ensure that the optimum mixture has a higher shear strength than conventional subballast and less swell pressure compared to the typical loads applied to the capping layer, the waste mixtures should satisfy $\emptyset_{\text {peak }}^{\prime} \geq 49^{\circ}$, and $P_{\text {swell }}<$ $30 \mathrm{kPa}$ (shaded region in Fig. 8), thus the ratio of SFS:CW $=7: 3$ could be selected as an optimum ratio.

The permeability $k$ and energy absorption property of all the mixtures with SFS:CW=7:3 satisfied the required range in Table 1. Fig. 9 shows that only mixtures with RC from $8 \sim 18.5 \%$ satisfy the required range based on particle breakage $(\mathrm{BI} \leq 2 \%)$ and shear strength $\left(\emptyset_{\text {peak }} \geq\right.$ $49^{\circ}$ ), and only mixtures with RC from $2 \sim 18 \%$ satisfy the required range of axial strain under cyclic loading $(\leq 2 \%)$ and swell pressure $\left(P_{\text {swell }}<30 \mathrm{kPa}\right)$. Therefore, the combined acceptable range of particle breakage, shear strength, axial strain, and swell pressure, the amount of $\mathrm{RC}$ in the waste mixtures should be between $8 \sim 18 \%$. It is interesting to note that $10 \%$ of RC is sufficient to improve substantially the energy-absorbing capacity of the waste mixtures, without influencing significantly the axial displacement and associated shear strength in both static and cyclic loading conditions. On this basis, $10 \%$ of RC can be taken as the optimum amount of RC.

In summary, the optimum mixture could be established as SFS63+CW27+RC10 (SFS:CW=7:3, and 10\% RC). While the results reported herein are promising, it is important to note that findings reported in this paper may not be applicable to all types of SFS+CW $+\mathrm{RC}$ mixtures because the geotechnical properties of these waste materials depend strongly on the original source and manufacturing processes. For this reason, it is strongly recommended that field trials be carried out on the selected SFS $+\mathrm{CW}+\mathrm{RC}$ mixtures to investigate their actual performance under cyclic loading. 
360 A comprehensive laboratory testing program was carried out for SFS+CW

$361+\mathrm{RC}$ mixtures to investigate the relevant geotechnical properties (permeability, stress-strain 362 behaviour, strain energy absorption, particle breakage, swell pressure and axial displacement 363 under cyclic loading). The testing program consisted of permeability tests, compaction tests, 364 drained consolidated monotonic and cyclic triaxial tests, swell pressure tests and sieving tests.

365 It was found as the amount of RC was increased in the waste mixtures, the permeability 366 coefficient increased, particle breakage decreased, extent of energy absorbed increased, and 367 the swell pressure decreased. However, the addition of RC should have an upper limit, 368 because a higher $\mathrm{RC}$ content also results in reduced shear strength and greater axial 369 displacement.

370 The ratio of SFS:CW governs the swell pressure and shear strength of the waste mixtures.

371 The increasing ratios of SFS:CW enhance the shear strength, but also induce higher swell 372 pressure.

373 In order to identify a suitable SFS+CW+RC mixture for subballast, the required range of the seven parameters (including gradation, permeability, peak friction angle, breakage index, swell pressure, strain energy density, and axial strain under cyclic loading) was formulated by comparing the geotechnical characteristics of conventional subballast. A ratio of 7:3 of

377 SFS:CW was selected based on the test results of swell pressure and shear strength. Then the 378 optimal RC content (10\%) was proposed based on the shear strength, particle breakage, swell 379 pressure, and the axial strain subjected to cyclic loading. Finally, the optimum mixture to 380 replace conventional subballast was established as SFS63+CW27+RC10 (63\% SFS, 27\% $\mathrm{CW}$, and $10 \% \mathrm{RC})$. 
Typically, capping materials used for rail substructure includes crushed rock, coarse sands and natural gravels and these materials cost around $\$ 45$ per tonne, whereas waste materials such as CW and SFS costs less than half. Therefore it will be economical attractive and environmental friendly to replace the natural subballast materials.

\section{Acknowledgements}

The first author would like to acknowledge the financial assistance provided by the China Scholarship Council. The assistance provided by industry (ASMS and South 32) in relation to the procurement of material used in this study is gratefully acknowledged. The assistance in the laboratory from Mr. Richard Berndt and the occasional technical feedback from A/Prof Cholachat Rujikiatkamjorn and Dr Vinod S. Jayan are appreciated.

\section{References}

Al-Khateeb, GG \& Ramadan, KZ 2015, 'Investigation of the Effect of Rubber on Rheological Properties of Asphalt Binders using Superpave DSR', Korean Society of Civil Engineers (KSCE) Journal of Civil Engineering, Vol. 19, Issue 1, January 2015, pp. 127-135.

ASTM D2434, American Society for Tests and Materials (2006b), standard test method for permeability of granular soils (constant head). ASTM International, West Conshohocken, PA, USA.

ASTM D5311/D5311M, American Society for Tests and Materials 2008 (R2012), Standard test method for load controlled cyclic triaxial strength of soil, ASTM International, West Conshohocken, PA, USA.

ASTM D6270, American Society for Tests and Materials 2008 (R2012), Standard practice for use of scrap tyres in civil engineering applications, ASTM D International, West Conshohocken, PA, USA. 

consolidated drained triaxial compression test for soils, ASTM International, West Conshohocken PA, USA.

Basma, AA, Al-Homoud, AS \& Husein, A 1995, 'Laboratory assessment of swell pressure of expansive soils', Applied Clay Science, vol. 9, no. 5, pp. 355-368. wash-slag blend as a structural fill', Ground Improvement, vol. 168, no. GI1, pp. 33-44.

Edil, T \& Bosscher, P 1994, 'Engineering properties of tyre chips and soil mixtures', Geotechnical Testing Journal, vol. 17, no. 4, pp. 453-464.

Ferreira, TM, Teixeira, PF \& Cardoso, R 2012, 'Impact of bituminous subballast on railroad track deformation considering atmospheric actions', J. Geotech. Geoenviron. Eng., vol. 137, no. 3, pp. 288-292. under Rail Track', J. Geotech. Geoenviron. Eng., vol. 10, no. 1061, pp. 338-341. of the coal wash and steel furnace slag blends as effective reclamation fill for port expansion',

421 Proceedings of the $7^{\text {th }}$ International Congress on Environmental Ceotechnics, Bouazza, A, 422 Yuan, STS \& Brown, B, (eds.), Melbourne, Australia, 10-14 November, pp. 972-979.

423 Heitor, A, Indraratna, B, Kaliboullah, CI, Rujikiatkamjorn, C \& McIntosh, G 2016, 'A study 424 on the drained and undrained shearing behaviour of compacted coal wash', J. Geotech. Geoenviron. Eng., ASCE DOI: 10.1061/(ASCE)GT.1943-5606.0001422. 
426 Indraratna, B 1994, 'Geotechnical Characterization of Blended Coals Tailings for 427 Construction and Rehabilitation Work', Quarterly Journal of Engineering Geology and Hydrogeology, vol. 27, pp. 353-361.

429

Indraratna, B, Lackenby, J \& Christie, D 2005, 'Effect of confining pressure on the 430 degradation of ballast under cyclic loading', Geotechnique, vol. 55, no. 4, pp. 325-328.

Indraratna, B, Salim, W \& Rujihiatkamjorn, C 2011, Advanced rail geotechnology-ballasted 432 track, CRC Press/Balkema, The Netherlands.

Indraratna, B, Biabani, MM \& Nimbalkar, S 2014, 'Behavior of Geocell-reinforced subballast 434 subjected to cyclic loading in plane-strain condition', J. Geotech. Geoenviron. Eng., vol. 141, 435 No. 1, pp. 04014081.

436 Gibson, N, Qi, X, Shenoy, A, Al-Khateeb, G, Kutay, ME, Andriescu, A, Stuart, K, 437 Youtcheff, J \& Harman, T 2012, 'Full-Scale Accelerated Performance Testing for Superpave and Structural Validation: Transportation Pooled Fund Study TPF 5(019) and SPR-2(174) Accelerated Pavement Testing of Crumb Rubber Modified Asphalt Pavements', Federal 440 Highway Administration (FHWA), Virginia, USA, FHWA Publications.

441 Kim, HK \& Santamarina, JC 2008, 'Sand-rubber mixtures (large rubber chips)', Canadian 442 Geotechnical Journal, vol. 45, pp. 1457-1466.

443 Leventhal, AR \& de Ambrosis, LP 1985, 'Waste disposal in coal mining - a geotechnical 444 analysis', Engineering Geology, vol. 22, no. 1, pp. 83-96.

445 Lim, T \& Chu, J 2006, 'Assessment of use of spent copper slag for land reclamation', Waste 446 Management Research, vol. 24, pp. 67-73. 
447 Marachi, ND, Chan, CK \& Seed, HB 1972, 'Evaluation of properties of rockfill materials', $J$. 448 Soil Mech. Found. Div. ASCE, vol. 98, No. 1, pp. 95-114.

449 NSW Environment Protection Authority (EPA), 2014. Resource Recovery Exemption, the 450 Protection of the Environment Operations (Waste) Regulation 2014 - The coal washery 451 rejects exemption (http://www.epa.nsw.gov.au/resources/waste/rre14-coal-wash-rejects.pdf)

NSW Environment Protection Authority (EPA), 2014. Resource Recovery Exemption the Protection of the Environment Operations (Waste) Regulation 2014 - The steel furnace slag exemption (http://www.epa.nsw.gov.au/resources/waste/rre14-steel-furnace-slag.pdf)

Navarro, FM \& Gamez, MCR 2012, 'Influence of crumb rubber on the indirect tensile strength and stiffness modulus of hot bituminous mixes', J. Mater. Civ. Eng., vol. 24, no. 6, pp. 715-724.

Qi, X, Shenoy, A, Al-Khateeb, G, Arnold, T, Gibson, N, Youtcheff, J \& Harman, T 2006, 'Laboratory Characterization and full-Scale Accelerated Performance Testing of Crumb Rubber Asphalts and Other Modified Asphalt Systems', Proceedings of the Asphalt Rubber Conference (ARC), San Diego, California, USA, October 2006.

Radampola, SS, Gurung, N, McSweeney, T \& Dhanasekar, M 2008, 'Evaluation of the properties of railway capping layer soil', Computers and Geotechnics, vol. 35, no. 5, pp. 719728.

Senetakis, K, Anastasiadis, A \& Pitilakis, K 2012, 'Dynamic properties of dry sand/rubber (SRM) and gravel/rubber (GRM) mixtures in a wide range of shearing strain amplitudes', Soil Dynamics and Earthquake Engineering, vol. 33, No. 1, pp. 38-53.

Sheikh, MN, Mashiri, M, Vinod, J \& Tsang, H 2013, 'Shear and Compressibility Behaviour of Sand-Tyre Crumb Mixtures', J. mater. Civ. Eng., vol. 25, pp. 1366-1374. 
Suiker, ASJ, Selig, ET \& Frenkel R 2005, 'Static and cyclic triaxial testing of ballast and

472 Tasalloti, SMA, Indraratna, B, Rujikiatkamjorn, C, Heitor, A \& Chiaro, G 2015, 'A 473 laboratory Study on the Shear Behaviour of Mixtures of Coal Wash and Steel Furnace Slag as 474 Potential Structural Fill', Geotechnical testing journal, vol. 38, no. 4, pp. 361-372.

475 Teixeira, PF, López-Pita, A, Casas-Esplugas, C, Bachiller, A \& Robusté, F 2006, 476 'Improvements in high-speed ballasted track design: Benefits of bituminous subballast layers', 477 Transportation Research Record 1943, pp. 43-49.

478 Trani, LDO \& Indraratna, B 2010, 'Assessment of subballast filtration under cyclic loading', 479 Journal of Geotechnical and Geoenvironmental Engineering, vol. 136, pp. 1519-1528.

$480 \mathrm{Xu}, \mathrm{MZ}$, Liu, JJ, Li, WZ \& Duan, WF 2015, 'Novel method to prepare activated crumb 481 rubber used for synthesis of activated crumb rubber modified asphalt', J. Mater. Civ. Eng., 482 vol. 27, no. 5, pp. 04014173.

483 Wang, G 2010, 'Determination of the expansion force of coarse steel slag aggregate', 484 Construction and Building Materials, vol. 24, No. 10, pp. 1961-1966.

485 Zheng, YF \& Kevin, SG 2000, 'Dynamic properties of granulated rubber/sand mixtures', 486 Geotechnical Testing Journal, vol. 23, No. 3, pp. 338-344. 
489 Fig. 1 PSD of the individual waste materials and the mixtures

490 Fig. 2 Permeability coefficient for different ratios of SFS:CW and different amount of RC

491 Fig. 3 Triaxial consolidated drained shearing of waste mixtures: (a) for different amount of

492 RC with SFS:CW=7:3; (b) for different ratios of SFS:CW with $10 \%$ RC

493 Fig. 4 Peak friction angle, breakage index, and strain energy density for different ratios of

494 SFS:CW and different amount of RC

495 Fig. 5 (a) Swell pressure for SFS+CW+RC mixtures with different ratios of SFS:CW; (b)

496 Swell pressure of SFS+CW+RC mixtures for different amount of RC (SFS:CW=7:3)

497 Fig. 6 Axial strain of SFS+CW+RC mixtures for different RC content

498

Fig. 7 Axial strain of SFS+CW+RC mixtures with different amount of RC after 50000 cycles

499

Fig. 8 Optimisation of the ratio of SFS:CW based on the shear strength and swell pressure of

500 waste mixtures with $10 \% \mathrm{RC}$

501

Fig. 9 Optimisation of RC content based on the peak friction angle, BI, swell pressure and

502 axial strain of waste mixtures with SFS:CW=7:3

503

504

505 


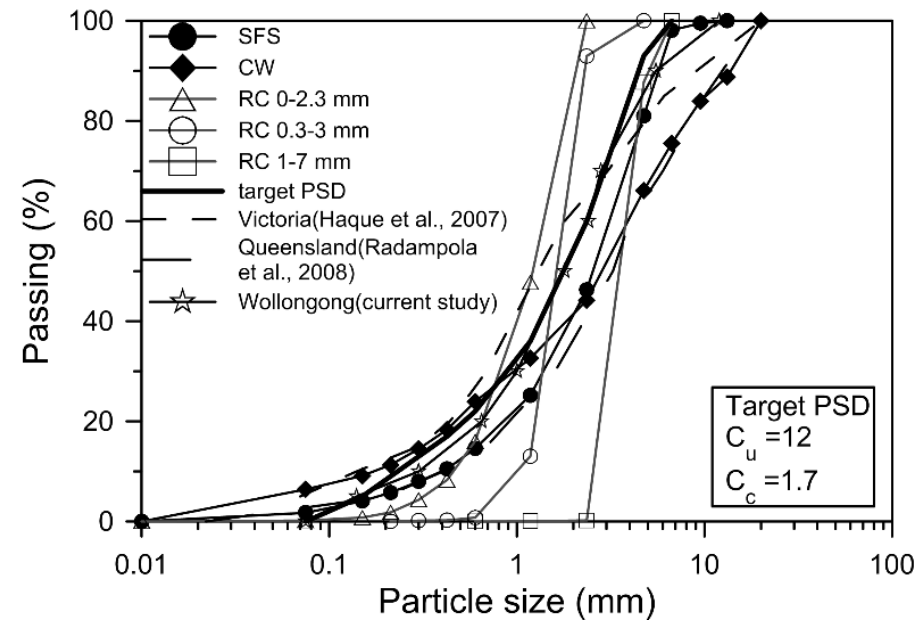

Fig. 1 PSD of the individual waste materials and the mixtures 


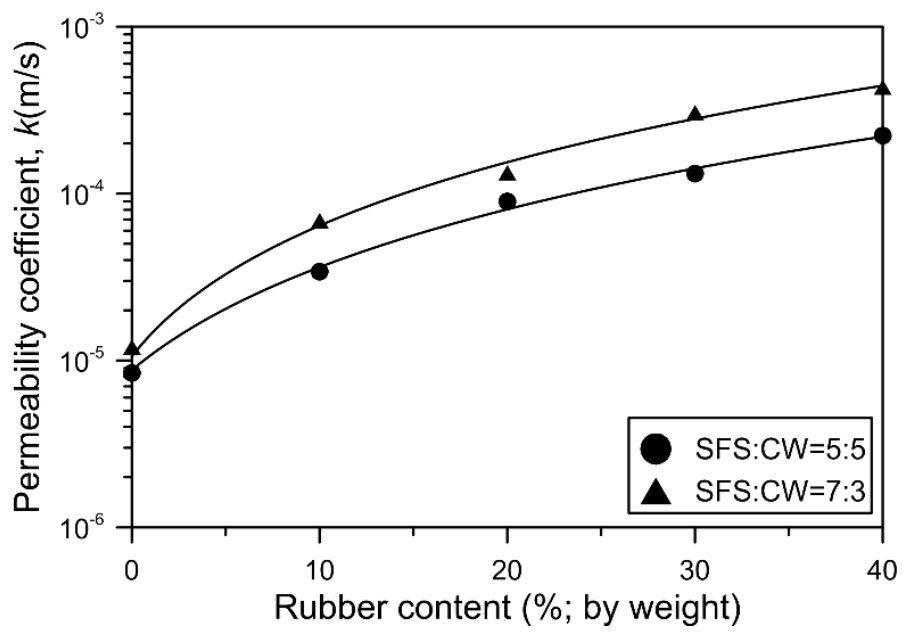

Fig. 2 Permeability coefficient for different ratios of SFS:CW and different amount of RC 


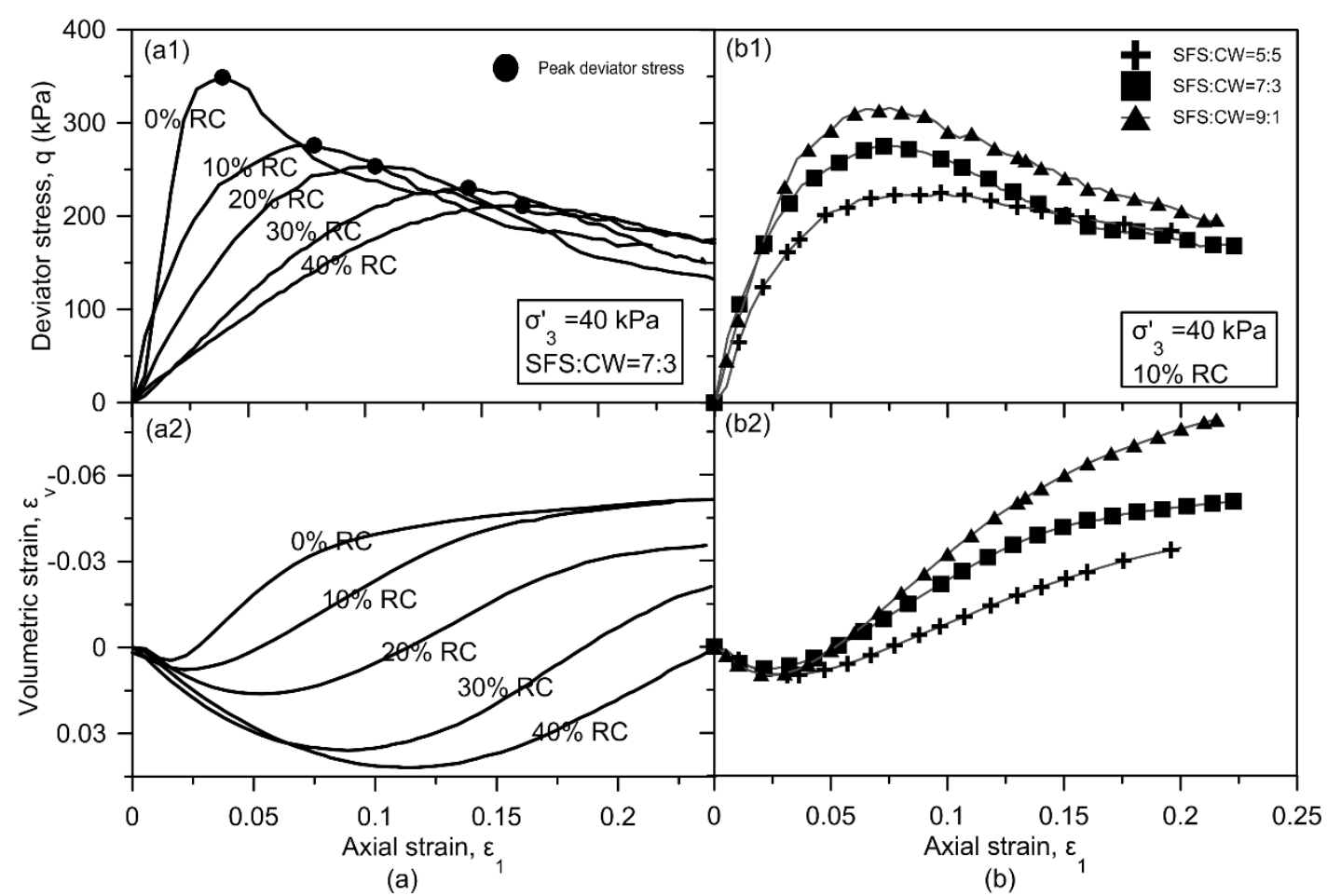

(a)

Fig. 3 Triaxial consolidated drained shearing of waste mixtures: (a) for different amount of RC with SFS:CW=7:3; (b) for different ratios of SFS:CW with 10\% RC 


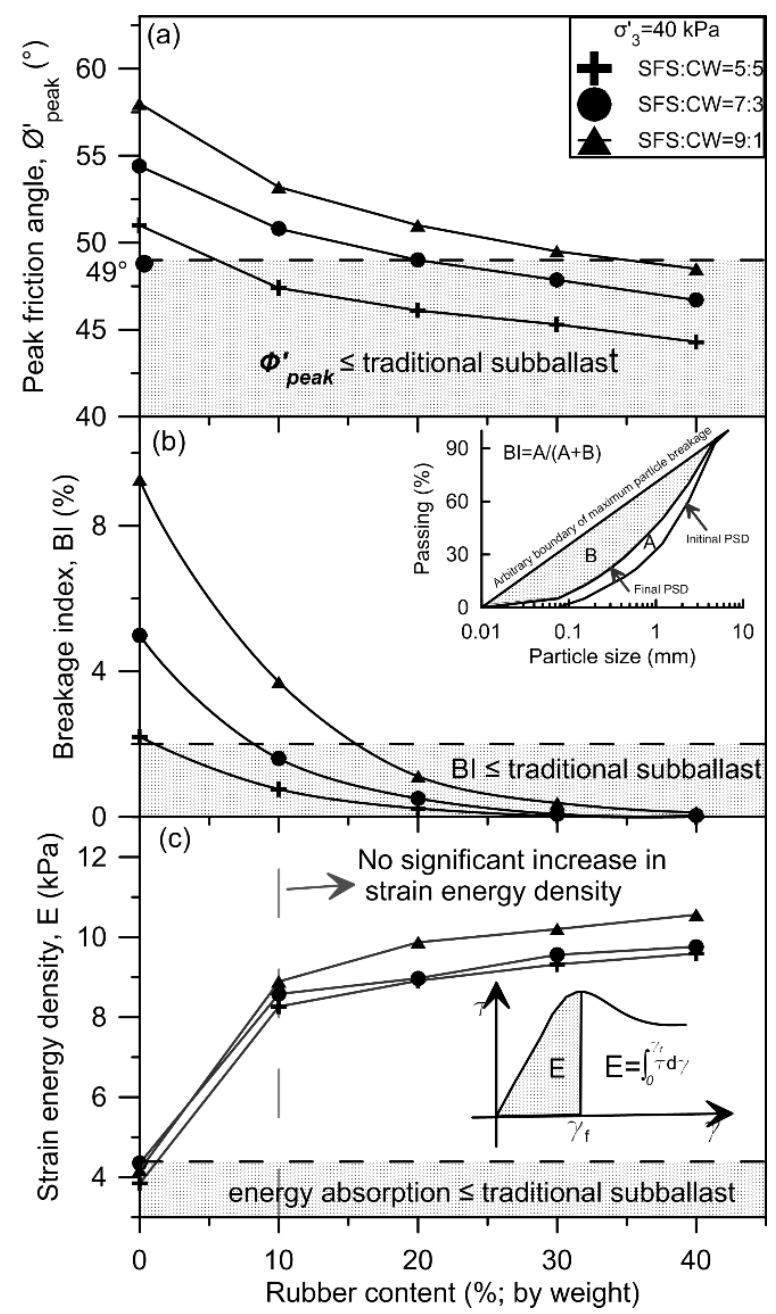

514 Fig. 4 Peak friction angle, breakage index, and strain energy density for different ratios of SFS:CW and different amount of RC 


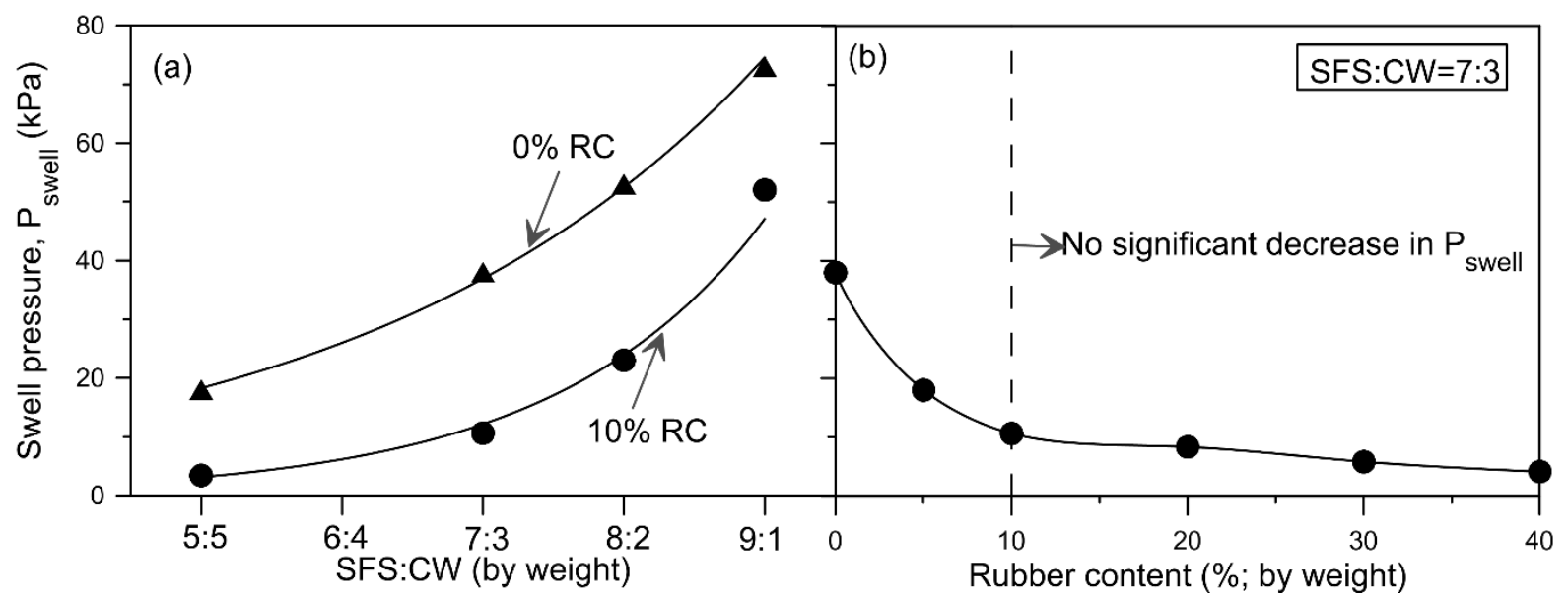

Fig. 5 (a) Swell pressure for SFS+CW+RC mixtures with different ratios of SFS:CW; (b) Swell pressure of SFS+CW+RC mixtures for different amount of RC (SFS:CW=7:3) 


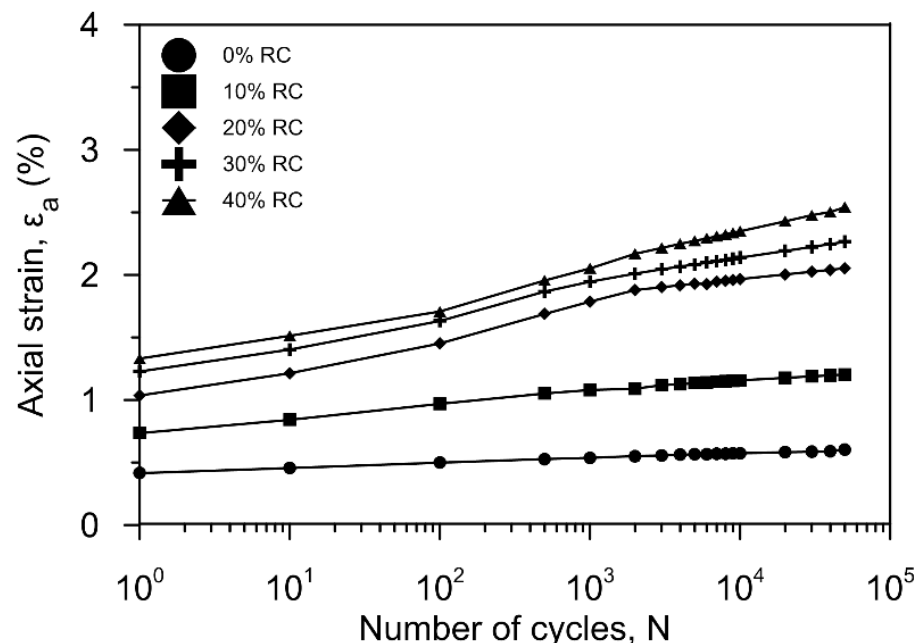

Fig. 6 Axial strain of SFS+CW+RC mixtures for different RC content 


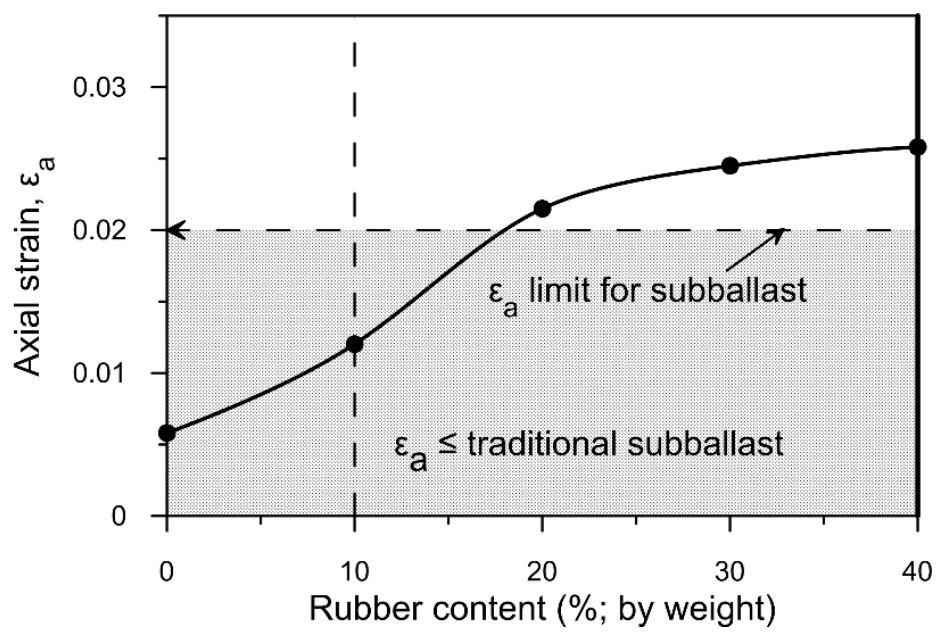

522 Fig. 7 Axial strain of SFS+CW+RC mixtures with different amount of RC after 50000 cycles 


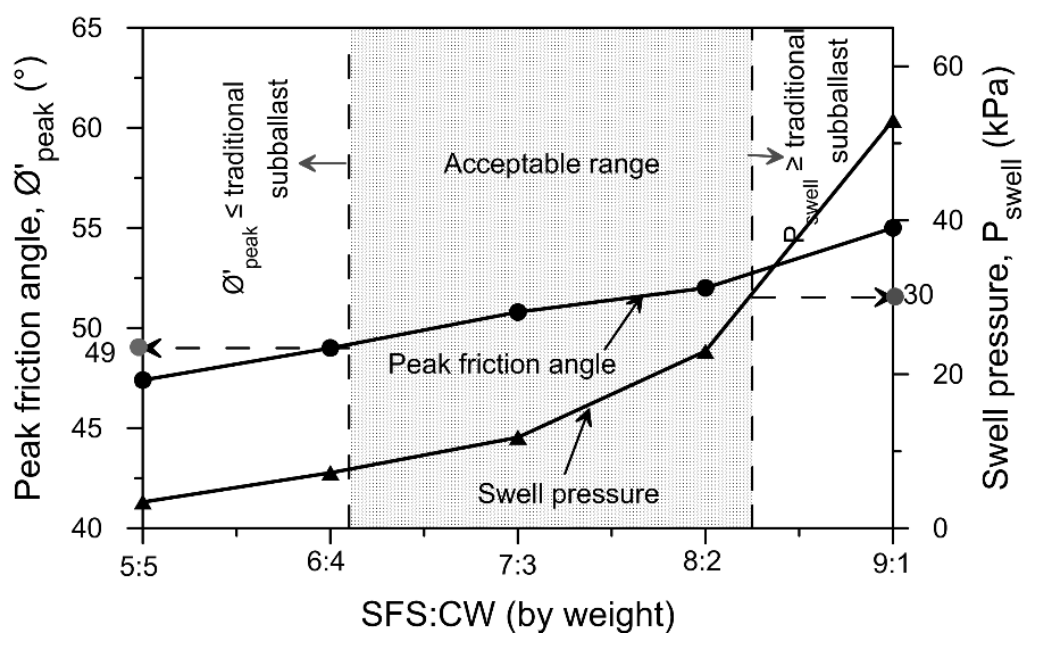

524 Fig. 8 Optimisation of the ratio of SFS:CW based on the shear strength and swell pressure of waste mixtures with $10 \% \mathrm{RC}$ 


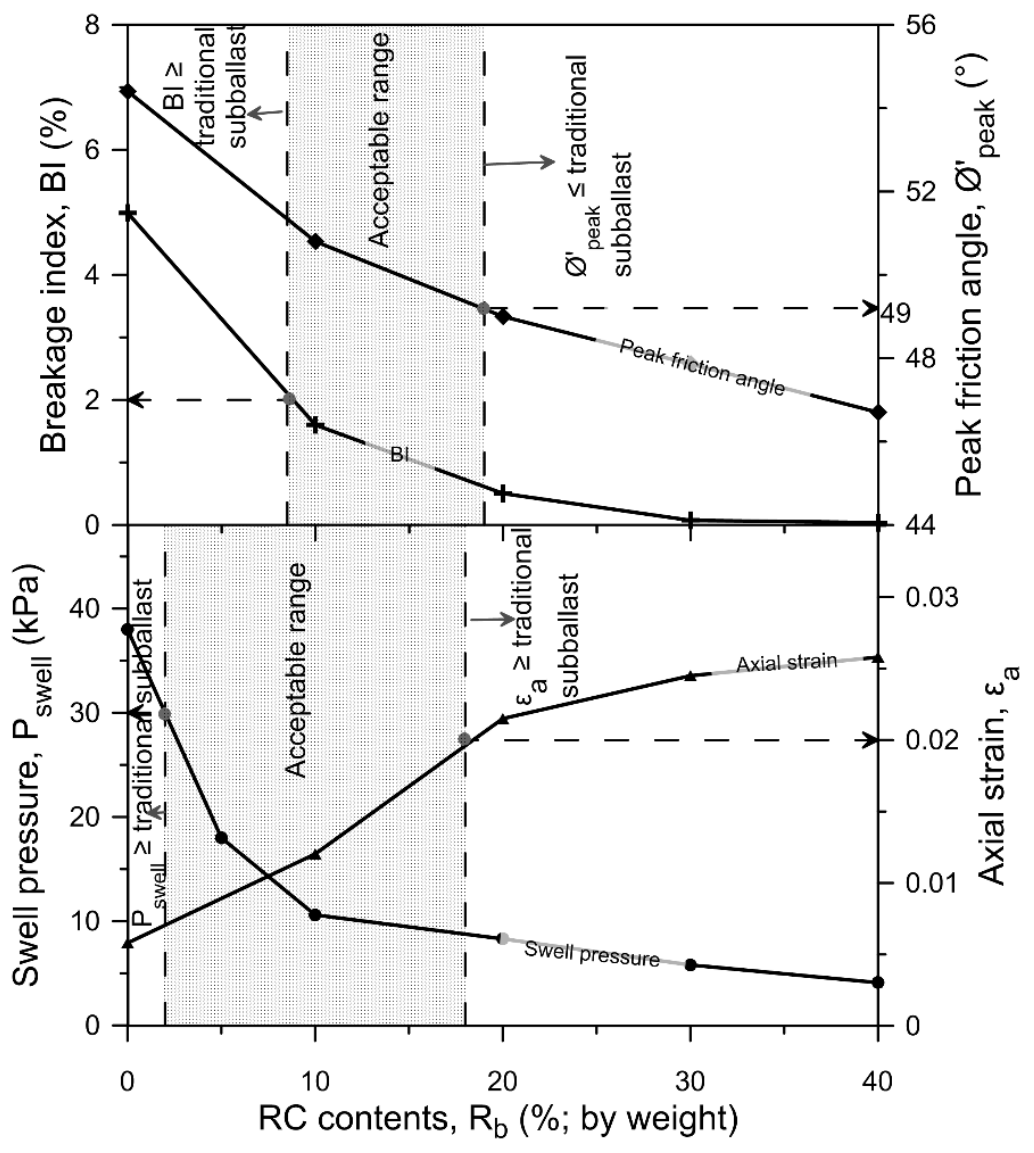

527 Fig. 9 Optimisation of RC content based on the peak friction angle, BI, swell pressure and axial strain of waste mixtures with SFS:CW=7:3 
$530 \quad$ List of Tables

531 Table 1 Parameters the required range used to evaluate SFS+CW+RC mixtures for subballast

532 Table 2 Typical chemical composition of CW and SFS

533 Table 3 Basic geotechnical properties of SFS, CW, RC, the SFS+CW+RC mixtures, and the

534 traditional subballast

535 Table 4 Peak friction angle, post-shearing breakage index (BI), and strain energy density

536 (after shearing at $\sigma_{3}^{\prime}=40 \mathrm{kPa}$ ), and swell pressure of SFS+CW+RC mixtures and the

537 traditional subballast 
Table 1 Parameters and the required range used to evaluate $\mathrm{SFS}+\mathrm{CW}+\mathrm{RC}$ mixtures for subballast

\begin{tabular}{ccc}
\hline Parameters & Required range & References \\
\hline Gradation & $\begin{array}{c}\text { similar with traditional } \\
\text { subballast }\end{array}$ & $\begin{array}{c}\text { Haque et al., 2007; } \\
\text { Radampola et al., 2008 }\end{array}$ \\
\hline Permeability coefficient & $10^{-5} \leq k \leq 10^{-3} \mathrm{~m} / \mathrm{sec}$ & Trani \& Indraratna, 2010 \\
\hline Peak friction angle & $\emptyset_{\text {peak }}^{\prime} \geq 49^{\circ}$ & current study \\
\hline The breakage index & $\mathrm{BI}<2 \%$ & current study \\
\hline swell pressure & $\mathrm{P}_{\text {swell }}<30 \mathrm{kPa}$ & Ferreira \&Teixeira, 2012 \\
\hline $\begin{array}{c}\text { Mean acceptable axial strain } \\
\text { (cyclic) }\end{array}$ & $\varepsilon_{a} \leq 0.02$ & Teixeira et al., 2006 \\
\hline Strain energy density & $\mathrm{E} \geq 4.39 \mathrm{kPa}$ & current study \\
\hline
\end{tabular}


Table 2 Typical chemical composition of CW and SFS

\begin{tabular}{cccc}
\hline & SFS & & CW \\
\hline Components & Proportion $(\%)$ & Components & Proportion $(\%)$ \\
$\mathrm{SiO}_{2}$ & 12.5 & Ash & 65.6 \\
$\mathrm{Al}_{2} \mathrm{O}_{3}$ & 2.8 & Carbon & 24.3 \\
$\mathrm{CaO}$ & 38.3 & Volatiles & 14.4 \\
$\mathrm{MgO}$ & 9.9 & Hydrogen & 1.90 \\
$\mathrm{Fe}_{2} \mathrm{O}_{3}$ & 30 & Nitrogen & 0.55 \\
$\mathrm{MnO}_{\mathrm{TiO}}$ & 3.7 & Sulphur & 0.23 \\
Others & 1.2 & Phospor & 0.02 \\
\hline
\end{tabular}

544 *Provided by the ASMS and the BHP Illawarra Coal. 
546 Table 3 Basic geotechnical properties of SFS, CW, RC, the SFS+CW+RC mixtures, and the 547 traditional subballast

\begin{tabular}{|c|c|c|c|c|c|c|c|}
\hline Material & SFS:CW & $\mathrm{RC}(\%)$ & $G_{s}$ & $\underset{\left(k N / m^{3}\right)}{\gamma_{d m a x}}$ & $\begin{array}{c}\text { OMC } \\
(\%)\end{array}$ & $e_{0}$ & $\begin{array}{c}k \\
(\mathrm{~m} / \mathrm{sec})\end{array}$ \\
\hline SFS & - & - & 3.43 & - & - & - & - \\
\hline $\mathrm{CW}$ & - & - & 2.11 & - & - & - & - \\
\hline $\mathrm{RC}$ & - & - & 1.15 & - & - & - & - \\
\hline SFS50+CW50 & \multirow{5}{*}{$5: 5$} & 0 & 2.61 & 18.60 & 12.5 & 0.449 & $\begin{array}{l}8.4 \\
\times 10^{-6} \\
\end{array}$ \\
\hline SFS45+CW45+RC10 & & 10 & 2.32 & 16.45 & 13 & 0.455 & $\begin{array}{l}3.4 \\
\times 10^{-5} \\
\end{array}$ \\
\hline SFS40+CW40+RC20 & & 20 & 2.08 & 14.70 & 15 & 0.461 & $\begin{array}{l}8.95 \\
\times 10^{-5} \\
\end{array}$ \\
\hline SFS35+CW35+RC30 & & 30 & 1.89 & 13.28 & 13.5 & 0.469 & $\begin{array}{c}1.32 \times \\
10^{-4} \\
\end{array}$ \\
\hline SFS30+CW30+RC40 & & 40 & 1.73 & 12.1 & 15 & 0.476 & $\begin{array}{c}2.23 \times \\
10^{-4} \\
\end{array}$ \\
\hline SFS54+CW36+RC10 & $6: 4$ & 10 & 2.41 & 16.77 & 13.5 & 0.471 & - \\
\hline SFS70+CW30 & \multirow{5}{*}{$7: 3$} & 0 & 2.89 & 20.30 & 11.5 & 0.470 & $\begin{array}{l}1.2 \\
\times 10^{-5} \\
\end{array}$ \\
\hline SFS63+CW27+RC10 & & 10 & 2.51 & 17.57 & 12.5 & 0.474 & $\begin{array}{l}6.86 \\
\times 10^{-5} \\
\end{array}$ \\
\hline SFS56+CW24+RC20 & & 20 & 2.22 & 15.50 & 13 & 0.479 & $\begin{array}{l}1.13 \\
\times 10^{-4} \\
\end{array}$ \\
\hline SFS49+CW21+RC30 & & 30 & 1.99 & 13.83 & 14 & 0.485 & $\begin{array}{l}3.05 \\
\times 10^{-4}\end{array}$ \\
\hline SFS42+CW18+RC40 & & 40 & 1.80 & 12.40 & 15 & 0.499 & $\begin{array}{l}4.35 \\
\times 10^{-4} \\
\end{array}$ \\
\hline SFS72+CW18+RC10 & $8: 2$ & 10 & 2.61 & 18.2 & 13.5 & 0.480 & - \\
\hline SFS90+CW10 & \multirow{5}{*}{$9: 1$} & 0 & 3.23 & 22.6 & 13 & 0.475 & - \\
\hline SFS81+CW9+RC10 & & 10 & 2.74 & 19.0 & 14 & 0.483 & - \\
\hline SFS72+CW8+RC20 & & 20 & 2.37 & 16.4 & 14.5 & 0.492 & - \\
\hline SFS63+CW7+RC30 & & 30 & 2.09 & 14.4 & 15 & 0.498 & - \\
\hline SFS54+CW6+RC40 & & 40 & 1.87 & 12.8 & 15 & 0.508 & - \\
\hline $\begin{array}{l}\text { Traditional subballast } \\
\text { (crushed rock) }\end{array}$ & - & - & 2.7 & 18.5 & 4.6 & 0.423 & - \\
\hline
\end{tabular}

549 The mixtures are expressed as SFS+CW+RC, and the numbers after SFS, CW, and RC are 550 the percentages of steel furnace slag, coal wash, and rubber crumbs by weight. 
Table 4 Peak friction angle, post-shearing breakage index (BI), and strain energy density (after shearing at ${\sigma^{\prime}}_{3}=40 \mathrm{kPa}$ ), and swell pressure of SFS+CW+RC mixtures and traditional subballast

\begin{tabular}{|c|c|c|c|c|c|c|}
\hline Materials & SFS:CW & $\mathrm{RC}(\%)$ & $\emptyset_{\text {peak }}^{\prime}\left({ }^{\circ}\right)$ & $\mathbf{P}_{\text {swell }}(k P a)$ & BI (\%) & $\mathrm{E}(\boldsymbol{k P a})$ \\
\hline SFS50+CW50 & \multirow{5}{*}{$5: 5$} & 0 & 51 & 18 & 9.27 & 3.85 \\
\hline SFS45+CW45+RC10 & & 10 & 47.4 & 3.4 & 3.71 & 8.27 \\
\hline SFS40+CW40+RC20 & & 20 & 46.1 & - & 1.11 & 8.91 \\
\hline SFS35+CW35+RC30 & & 30 & 44.5 & - & 0.38 & 9.32 \\
\hline SFS30+CW30+RC40 & & 40 & 43.9 & - & 0.13 & 9.59 \\
\hline SFS54+CW36+RC10 & $6: 4$ & 10 & 49 & - & - & - \\
\hline SFS70+CW30 & \multirow{6}{*}{$7: 3$} & 0 & 54.4 & 38 & 4.99 & 4.35 \\
\hline SFS66.5+CW28.5+RC5 & & 5 & - & 18.2 & - & - \\
\hline SFS63+CW27+RC10 & & 10 & 50.8 & 10.6 & 1.60 & 8.58 \\
\hline SFS56+CW24+RC20 & & 20 & 49 & 8.3 & 0.503 & 8.97 \\
\hline SFS49+CW21+RC30 & & 30 & 47.86 & 5.8 & 0.073 & 9.56 \\
\hline SFS42+CW18+RC40 & & 40 & 46.6 & 4.1 & 0.038 & 9.76 \\
\hline SFS80+CW20 & \multirow{2}{*}{$8: 2$} & 0 & - & 53 & - & - \\
\hline SFS72+CW18+RC10 & & 10 & 52 & 23 & - & - \\
\hline SFS90+CW10 & \multirow{5}{*}{$9: 1$} & 0 & 60 & 73 & 2.2 & 4.18 \\
\hline SFS81+CW9+RC10 & & 10 & 55 & 52 & 0.76 & 8.89 \\
\hline SFS72+CW8+RC20 & & 20 & 52 & - & 0.23 & 9.87 \\
\hline SFS63+CW7+RC30 & & 30 & 50.5 & - & 0.02 & 10.20 \\
\hline SFS54+CW6+RC40 & & 40 & 49 & - & 0 & 10.56 \\
\hline $\begin{array}{l}\text { Traditional subballast } \\
\text { (crushed rock) }\end{array}$ & & - & 49 & - & 2.0 & 4.39 \\
\hline
\end{tabular}

